\title{
Smoking-associated risks of conventional adenomas and serrated polyps in the colorectum
}

\author{
Jane C. Figueiredo $\cdot$ Seth D. Crockett $\cdot$ Dale C. Snover $\cdot$ Carolyn B. Morris • \\ Gail McKeown-Eyssen • Robert S. Sandler • Dennis J. Ahnen • Douglas J. Robertson • \\ Carol A. Burke - Robert S. Bresalier • James M. Church • Timothy R. Church • \\ John A. Baron
}

Received: 21 May 2014/ Accepted: 12 December 2014/Published online: 24 December 2014

(C) The Author(s) 2014. This article is published with open access at Springerlink.com

\begin{abstract}
Purpose Prior studies suggest cigarette smoking is associated with 1.5- to twofold increased risk of colorectal adenomas and possibly a higher risk of serrated polyps. Further clarification of risk differences between adenomas and serrated polyps is needed with regard to co-occurrence and polyp location.

Methods We conducted a combined analysis of conventional adenoma and serrated polyp occurrence using individual-level data from 2,915 patients participating in three colonoscopy-based clinical trials. All participants had $\geq 1$ adenomas removed at baseline and were followed for up to 4 years. Smoking habits and other lifestyle factors were collected at baseline using questionnaires. We used generalized linear regression to estimate risk ratios and $95 \%$ confidence intervals.
\end{abstract}

J. C. Figueiredo $(\bowtie)$

Department of Preventive Medicine, Keck School of Medicine, University of Southern California, Los Angeles, CA, USA

e-mail: janefigu@usc.edu

S. D. Crockett - C. B. Morris · R. S. Sandler · J. A. Baron Division of Gastroenterology and Hepatology, University of North Carolina School of Medicine, Chapel Hill, NC, USA

D. C. Snover

Department of Laboratory Medicine and Pathology, University of Minnesota Medical School, Minneapolis, MN, USA

G. McKeown-Eyssen

Dalla Lana School of Public Health, University of Toronto,

Toronto, ON, Canada

D. J. Ahnen

Division of Gastroenterology, Department of Veterans Affairs Eastern Colorado Health Care System, University of Colorado School of Medicine, Denver, CO, USA
Results Smokers were at slightly increased risk of adenomas compared to never smokers [current: RR 1.29 (95\% CI 1.11-1.49) and former: RR 1.18 (1.05-1.32)]. Smoking was associated with greater risk of serrated polyps [current: RR 2.01 (1.66-2.44); former: RR 1.42 (1.20-1.68)], particularly in the left colorectum. Associations between current smoking and occurrence of serrated polyps only [RR 2.33 (1.76-3.07)] and both adenomas and serrated polyps [RR 2.27 (1.68-3.06)] were more pronounced than for adenomas only [RR $1.31(1.08-1.58)]$. Results were similar for other smoking variables and did not differ by gender or for advanced adenomas.

Conclusions Cigarette smoking has only a weak association with adenomas, but is associated with a significantly increased risk of serrated polyps, particularly in the left colorectum. Since a minority of left-sided serrated polyps

D. J. Robertson

White River Junction VA Medical Center, Geisel School of Medicine at Dartmouth, Hanover, NH, USA

\section{A. Burke}

Department of Gastroenterology and Hepatology, Cleveland Clinic, Cleveland, OH, USA

\section{R. S. Bresalier}

Department of Gastroenterology, The University of Texas MD Anderson Cancer Center, Houston, TX, USA

J. M. Church

Department of Colorectal Surgery, Cleveland Clinic, Cleveland, $\mathrm{OH}, \mathrm{USA}$

T. R. Church

Division of Environmental Health Sciences, School of Public Health, University of Minnesota, Minneapolis, MN, USA 
is thought to have malignant potential, the role of smoking in initiation phases of carcinogenesis is uncertain.

Keywords Smoking - Tobacco - Colorectal - Adenomas · Serrated polyps

\section{Introduction}

Cigarette smoking is a known risk factor for cancer in several organs, including those not directly exposed to inhaled smoke [1]. In the colorectum, smoking has been inconsistently associated with the development of cancer, but recent meta-analyses showed a moderate increase in risk [2-4]. Studies examining conventional adenomas (also called "adenomatous polyps" or "adenomas"), the precursor lesions to the majority of colorectal cancers (CRC), have observed a more consistent association with smoking [5]. A recent meta-analysis found that current smokers had a twofold elevation in risk of conventional adenomas compared to never smokers (OR 2.14; 95 \% CI 1.86-2.46), with a more pronounced association with advanced adenomas [5]. Some [6, 7] but not all [8, 9] studies have suggested that smoking is associated with a higher risk of adenomas occurring in the left colorectum compared to the right colon. Several other studies have also identified duration of tobacco use as a relevant factor [10-15].

It is now well recognized that conventional adenomas are not the sole precursor lesions for CRC. The family of serrated polyps includes hyperplastic polyps (HPs), which are not thought to have significant malignant potential, and two premalignant lesions, sessile serrated adenomas/polyps (SSA/Ps) and traditional serrated adenomas (TSAs), which give rise to up to one-third of sporadic CRC [16]. HPs, SSA/Ps, and TSAs represent roughly 85, 15, and $1 \%$ of serrated polyps, respectively [17]. In contrast to conventional adenomas, there is limited understanding of the risk factors and natural history of premalignant serrated polyps [18]. A few epidemiologic studies have reported associations between smoking and the development of serrated polyps in general with some inconsistencies [9-12, 19]. Morimoto et al. found that smoking was associated with an increased risk of serrated polyps, but not of adenomas [10]. Similarly, two other investigations also reported that smoking was associated with a greater risk of serrated polyps than adenomas [6, 19]. All three studies [6, 10, 19] found that the smoking-associated risk was highest for cooccurrence of adenomas and serrated polyps. This pattern of findings has led to the hypothesis that the co-occurrence of both adenomas and serrated polyps may represent a specific phenotype, which could explain the apparent associations of smoking with risk of adenomas that has been reported in other studies [10]. However, another recent study did not show evidence of a separate phenotype [20], shedding doubt on this phenomenon. Here, we expand upon our findings $[8,21]$ to report the combined results from three clinical trials with a total of 2,915 participants regarding the associations of recency, intensity, pack-years, duration, and timing of smoking with risk of conventional colorectal adenomas and serrated polyps considering size, concurrence, location, and histology.

\section{Methods}

Study design

We conducted an analysis using individual-level data from three clinical trials conducted by the Polyp Prevention Study Group In brief, all three trials were randomized, double-blind, placebo-controlled trials to test the efficacy of selected agents for the prevention of colorectal adenomas in individuals with a personal history of these polyps. In the Antioxidant Polyp Prevention Study (APPS), 864 individuals were randomized to beta-carotene $(25 \mathrm{mg}$ daily), vitamin C (1 g daily), vitamin E (400 mg daily), beta-carotene plus vitamins $\mathrm{C}$ and $\mathrm{E}$, or placebo [8, 22]. Similarly, the Calcium Polyp Prevention Study (CPPS) had 930 subjects were randomized to calcium carbonate [3 $\mathrm{g}$ (1,200 $\mathrm{mg}$ of elemental calcium) daily] or placebo [23]. In AFPPS (the Aspirin/Folic Acid Polyp Prevention Study), 1,121 subjects were randomized to one of three aspirin groups (placebo, 81 or $321 \mathrm{mg} /$ day) and to one of two folic acid groups (placebo or $1 \mathrm{mg} /$ day) [24]. Follow-up colonoscopic examinations were expected at 3 years after the baseline examination. No individual participated in more than one trial.

Questionnaires-smoking and other risk factors

All participants in these three trials completed similar questionnaires regarding personal characteristics, medical history, and lifestyle habits. Cigarette smoking status was assessed at study entry through a questionnaire. Current smokers responded as to the number of cigarettes smoked daily, current and former smokers indicated the age of initiation of smoking and the most cigarettes they routinely smoked a day for at least a year, and former smokers indicated the age at smoking cessation and the number of cigarettes per day they formerly smoked.

Study outcomes

Polyp occurrence in all studies was determined by colonoscopy. Records for all large bowel procedures (endoscopy 
or surgery) were obtained. Slides for all tissue removed from the bowel after the baseline exam were obtained and sent to a single study pathologist (DCS) for uniform review. Polyps were classified as conventional adenomas or serrated lesions, which included sessile serrated adenoma/polyps, traditional serrated adenomas, and HPs. Since these studies were completed before the current nomenclature regarding classification of serrated polyps was developed, all serrated polyps of any type were analyzed as a group. Large serrated polyps were defined as lesions equal to or greater than $1 \mathrm{~cm}$ in estimated diameter, as assessed by the endoscopist. Adenomas were subclassified as tubular, tubulovillous, or villous. Advanced adenomas were considered lesions with any villous histology, size greater than or equal to $1 \mathrm{~cm}$, or high-grade dysplasia/ cancer as previously described by the Polyp Prevention Group [8, 22, 23] and others [25]. Serrated polyps were considered as a separate end point. Polyps occurring in the cecum, ileum, ascending and transverse colon were considered right-sided, and lesions occurring in the splenic flexure, descending colon, sigmoid colon or rectum were considered left-sided. For APPS and CPPS, we included findings occurring on exams after the year one colonoscopy up to and including the year four surveillance exam. For AFPPS, we included findings more than 1 year after randomization up to and including the year three surveillance exam.

\section{Statistical Methods}

Chi-square and Student's $t$ tests (for categorical and continuous variables, respectively) were used to compare demographics and baseline characteristics of participants in the pooled trials. Generalized linear models were used to compute crude and adjusted risk ratios (RR) of the association between smoking and risk of each of the precursor lesions of interest. Linear trends were assessed between smoking groups per end point by contrasting parameter estimates calculated from the models. The end points of interest were as follows: (a) one or more conventional adenoma (irrespective of whether there was a serrated lesion present); (b) one or more serrated polyps (irrespective of conventional adenomas); and (c) concurrent conventional adenomas and serrated lesions. RR and $95 \%$ confidence intervals (CI) were adjusted for age, sex, clinical center, and trial. Additionally, the RR of outcomes of conventional adenoma only, serrated polyps only, and concurrent conventional adenomas and serrated polyps were compared side-by-side using a common control group to compare RR and $95 \% \mathrm{CI}$ associated with conventional adenomas only, serrated only, and conventional adenomas and serrated polyps jointly.
The possibility that gender modified the smoking associations was assessed in these models with the use of interaction terms and Wald tests (with and without adjustment for other variables). We also assessed associations for polyps by location in the bowel and (for adenomas) advanced features. To ensure associations between smoking variables and risk did not differ by treatment groups in the individual trials, we examined these associations within placebo and treatment groups.

\section{Results}

In total, 2,915 individuals were included in the three trials (Table 1). Most participants were male (70.9\%), and the overall mean age was 59.7 years (SD 9.3). Of the 2,667 subjects with end-point data, $973(36.4 \%)$ were found to have at least one conventional adenoma and 633 (23.7\%) had at least one serrated polyp during the follow-up period. Among individuals who had one or more serrated polyps during follow-up, $301(47.6 \%)$ also had one or more concurrent adenomas. Current smoking was associated with an increased risk of one or more adenomas (RR 1.29, $95 \%$ CI 1.11-1.49) and former smoking with a slightly lower, but still significantly increased risk (RR 1.18, $95 \%$ CI 1.05-1.32, $p$-trend for categories of smoking $=0.001$, Table 2) relative to never smoking. Smoking intensity (number of cigarettes per day) did not show a significant trend $(p=0.17)$; however, duration of smoking was modestly associated with an increasing rising trend, as the highest two levels of exposure were associated with the largest risk of adenomas versus never smokers (25 to $<35$ years: RR 1.28, $95 \%$ CI 1.09-1.49; and $\geq 35$ years: RR 1.21, $95 \%$ CI 1.05-1.41, $p$-trend $=0.006)$. Former smokers had a reduced risk of conventional adenomas compared to current smokers, particularly for those who quit between 1 and $<20$ years prior to study entry (RR 0.84, $95 \%$ CI 0.73-0.98). RR estimates for advanced adenomas were similar to the overall RRs, though with wider CI compared to tubular adenomas, reflecting sample size differences (Table 2).

Current and former smoking was associated with an increased risk of one or more serrated polyps on follow-up colonoscopy (RR 2.01, $95 \%$ CI 1.66-2.44; and RR 1.42, $95 \%$ CI 1.20-1.68, respectively, $p$-trend <0.0001) (Table 2). There was a significant trend of increasing risk with greater levels of pack-years; compared to never smokers, those with $>75$ pack-year smoking history had a RR of serrated polyps of 1.96 (95\% CI 1.50-2.56, p-trend $<0.0001)$. Both smoking intensity and duration also displayed trends of increasing risk with increasing exposure. For smokers of $>35$ years, the RR of serrated polyps was 2.12 (95\% CI 1.75-2.57). In addition, smoking cessation 
Table 1 Characteristics of the study populations in the Polyp Prevention Studies

\begin{tabular}{|c|c|c|c|c|}
\hline Characteristics & APPS & CPPS & AFPPS & All trials \\
\hline Participants, $(n)$ & 864 & 930 & 1,121 & 2,915 \\
\hline Participants with follow-up data, $(n)$ & 751 & 832 & 1,084 & 2,667 \\
\hline Duration (recruitment to end of treatment, mean \pm SD), (years) & $4.1 \pm 0.3$ & $4.0 \pm 0.4$ & $3.0 \pm 0.5$ & $3.6 \pm 0.7$ \\
\hline Age at randomization (mean $\pm \mathrm{SD})$, (years) & $61.2 \pm 8.3$ & $61.0 \pm 9.1$ & $57.4 \pm 9.6$ & $59.7+9.3$ \\
\hline Male sex, $n(\%)$ & $684(79.2)$ & $672(72.2)$ & $712(63.5)$ & 2,068 (70.9) \\
\hline Body mass index (mean $\pm \mathrm{SD})(\mathrm{kg} / \mathrm{m})$ & $26.9 \pm 4.1$ & $27.4 \pm 4.4$ & $27.4 \pm 4.5$ & $27.3 \pm 4.3$ \\
\hline Colon or colorectal cancer in first-degree relative, $n(\%)^{\mathrm{b}}$ & $165(19.5)$ & $194(23.9)$ & $341(37.3)$ & $700(24.0)$ \\
\hline \multicolumn{5}{|l|}{ Treatment group, $n(\%)$} \\
\hline Placebo & $214(24.8)$ & $466(50.1)$ & $169(16.6)^{\mathrm{a}}$ & \\
\hline Beta-carotene & $217(25.1)$ & - & - & \\
\hline Beta-carotene, vitamin $\mathrm{C}$, and vitamin $\mathrm{E}$ & $208(24.1)$ & - & - & \\
\hline Vitamin $\mathrm{C}$ and vitamin $\mathrm{E}$ & $214(24.8)$ & - & - & \\
\hline Calcium & - & $464(49.9)$ & - & \\
\hline Folic acid & - & - & $516(50.5)$ & \\
\hline Aspirin $81 \mathrm{mg}$ & - & - & 377 (33.6) & \\
\hline Aspirin $325 \mathrm{mg}$ & - & - & $372(33.2)$ & \\
\hline Alcohol (mean \pm SD), drinks per day & $0.84 \pm 1.61$ & $0.60 \pm 1.12$ & $0.63 \pm 1.06$ & $0.68 \pm 1.3$ \\
\hline \multicolumn{5}{|l|}{ Smoking status } \\
\hline Never & $268(31.7)$ & $309(33.2)$ & $481(43.0)$ & $1,058(36.6)$ \\
\hline Former & $389(46.0)$ & $442(47.5)$ & $473(42.3)$ & $1,304(45.1)$ \\
\hline Current & $188(22.3)$ & $179(19.3)$ & $164(14.7)$ & $531(18.4)$ \\
\hline \multicolumn{5}{|l|}{ Pack-years } \\
\hline None & $268(59.0)$ & $309(41.2)$ & $481(43.2)$ & $1,058(45.6)$ \\
\hline 0 to $<30$ & $22(4.8)$ & $205(27.3)$ & $319(28.6)$ & $546(23.6)$ \\
\hline 30 to $<75$ & $90(19.8)$ & $163(21.7)$ & $253(22.7)$ & $506(21.8)$ \\
\hline$\geq 75$ & $74(16.3)$ & $73(9.7)$ & $61(5.4)$ & $208(9.0)$ \\
\hline \multicolumn{5}{|l|}{ Intensity (number of cigarettes/day) } \\
\hline None & $268(32.2)$ & $309(33.4)$ & $481(43.0)$ & $1,058(36.8)$ \\
\hline 0 to $<20$ & $82(9.8)$ & $108(11.7)$ & $163(14.6)$ & $353(12.3)$ \\
\hline 20 to $<30$ & $250(30.0)$ & $292(31.5)$ & $307(27.5)$ & $849(29.5)$ \\
\hline$\geq 30$ & $233(28.0)$ & $217(23.4)$ & $167(14.9)$ & $617(21.5)$ \\
\hline \multicolumn{5}{|l|}{ Duration (years) } \\
\hline None & $268(32.5)$ & $309(41.1)$ & $481(43.1)$ & $1,058(39.3)$ \\
\hline 0 to $<25$ & $177(21.5)$ & $193(25.7)$ & $299(26.8)$ & $669(24.8)$ \\
\hline 25 to $<35$ & $117(14.2)$ & $129(17.2)$ & $158(14.2)$ & $404(15.0)$ \\
\hline$\geq 35$ & $263(31.9)$ & $121(16.1)$ & $178(15.9)$ & $562(20.9)$ \\
\hline \multicolumn{5}{|l|}{ Time since quitting (years) } \\
\hline None & $205(36.5)$ & $189(30.5)$ & $176(27.6)$ & $570(31.4)$ \\
\hline 1 to $<20$ & $238(42.4)$ & $284(45.8)$ & $262(41.1)$ & $784(43.1)$ \\
\hline$\geq 20$ & $118(21.0)$ & $147(23.7)$ & $199(31.2)$ & $464(25.5)$ \\
\hline \multicolumn{5}{|l|}{ Adenoma characteristics (at baseline) } \\
\hline Number (Mean \pm SD) & $1.87 \pm 1.34$ & $1.88 \pm 1.40$ & $1.58 \pm 0.98$ & $1.9 \pm 1.3$ \\
\hline Advanced adenomas, $n(\%)$ & $348(40.3)$ & $329(19.6)$ & $325(29.0)$ & $1,002(34.4)$ \\
\hline Right-sided location, $n(\%)$ & $333(38.5)$ & $400(23.8)$ & $503(44.9)$ & $1,236(42.4)$ \\
\hline
\end{tabular}

Counts do not necessarily add to the total sum due to missing data

${ }^{\text {a }}$ PPS 3 used a $2 \times 3$ factorial design, and counts in this table for folic acid and aspirin are greater than the total in the study. Total number in the placebo group represents the number of individuals who did not receive either folic acid or aspirin $81 / 325 \mathrm{mg}$

b PPS1 and PPS2 collected family history with colon cancer; PPS3 specified colorectal cancer 
Table 2 Association between cigarette smoking and risk of colorectal precursor lesions

\begin{tabular}{|c|c|c|c|c|c|c|c|c|}
\hline & \multicolumn{2}{|c|}{ One or more adenomas } & \multicolumn{2}{|c|}{$\begin{array}{l}\text { One or more advanced } \\
\text { adenomas }\end{array}$} & \multicolumn{2}{|c|}{$\begin{array}{l}\text { One or more small tubular } \\
\text { adenomas }\end{array}$} & \multicolumn{2}{|c|}{ One or more serrated polyps } \\
\hline & $n$ events & $\mathrm{RR}^{\mathrm{a}}(95 \% \mathrm{CI})$ & $n$ events & $\mathrm{RR}^{\mathrm{a}}(95 \% \mathrm{CI})$ & $n$ events & $\mathrm{RR}^{\mathrm{a}}(95 \% \mathrm{CI})$ & $n$ events & $\mathrm{RR}^{\mathrm{a}}(95 \% \mathrm{CI})$ \\
\hline \multicolumn{9}{|l|}{ Status } \\
\hline Never & 315 & 1.00 (ref) & 76 & 1.00 (ref) & 267 & 1.00 (ref) & 178 & 1.00 (ref) \\
\hline Former & 472 & $1.18(1.05,1.32)$ & 124 & $1.26(0.95,1.66)$ & 396 & $1.15(1.01,1.32)$ & 298 & $1.42(1.20,1.68)$ \\
\hline Current & 173 & $1.29(1.11,1.49)$ & 41 & $1.29(0.90,1.86)$ & 153 & $1.33(1.12,1.57)$ & 152 & $2.01(1.66,2.44)$ \\
\hline$p$-trend & & 0.001 & & 0.18 & & 0.001 & & $<0.0001$ \\
\hline \multicolumn{9}{|l|}{ Pack-years } \\
\hline None & 315 & 1.00 (ref) & 76 & 1.00 (ref) & 267 & 1.00 (ref) & 178 & 1.00 (ref) \\
\hline 0 to $<30$ & 205 & $1.23(1.07,1.43)$ & 56 & $1.44(1.02,2.03)$ & 167 & $1.20(1.02,1.42)$ & 125 & $1.30(1.06,1.60)$ \\
\hline 30 to $<75$ & 184 & $1.20(1.04,1.39)$ & 48 & $1.29(0.91,1.83)$ & 157 & $1.22(1.03,1.44)$ & 153 & $1.84(1.52,2.22)$ \\
\hline$\geq 75$ & 68 & $1.22(1.00,1.52)$ & 18 & $1.22(0.74,2.00)$ & 58 & $1.23(0.97,1.56)$ & 56 & $1.96(1.50,2.56)$ \\
\hline$p$-trend & & 0.09 & & 0.56 & & 0.11 & & $<0.0001$ \\
\hline \multicolumn{9}{|c|}{ Intensity (number of cigarettes/day) } \\
\hline None & 315 & 1.00 (ref) & 76 & 1.00 (ref) & 267 & 1.00 (ref) & 178 & $1.00(\mathrm{ref})$ \\
\hline 0 to $<20$ & 132 & $1.27(1.08,1.50)$ & 33 & $1.28(0.86,1.89)$ & 114 & $1.30(1.08,1.56)$ & 67 & $1.17(0.92,1.50)$ \\
\hline 20 to $<30$ & 305 & $1.22(1.07,1.38)$ & 76 & $1.25(0.92,1.70)$ & 255 & $1.19(1.03,1.38)$ & 234 & $1.80(1.51,2.13)$ \\
\hline$\geq 30$ & 201 & $1.13(0.98,1.31)$ & 52 & $1.23(0.87,1.75)$ & 175 & $1.14(0.97,1.35)$ & 145 & $1.57(1.29,1.92)$ \\
\hline$p$-trend & & 0.17 & & 0.30 & & 0.25 & & $<0.0001$ \\
\hline \multicolumn{9}{|c|}{ Duration (years) } \\
\hline None & 315 & 1.00 (ref) & 76 & 1.00 (ref) & 267 & 1.00 (ref) & 178 & 1.00 (ref) \\
\hline 0 to $<25$ & 237 & $1.17(1.02,1.34)$ & 61 & $1.27(0.92,1.76)$ & 198 & $1.14(0.98,1.34)$ & 151 & $1.31(1.09,1.59)$ \\
\hline 25 to $<35$ & 155 & $1.28(1.09,1.49)$ & 40 & $1.32(0.92,1.92)$ & 131 & $1.27(1.06,1.51)$ & 90 & $1.42(1.14,1.78)$ \\
\hline$\geq 35$ & 195 & $1.21(1.05,1.40)$ & 47 & $1.13(0.79,1.61)$ & 170 & $1.23(1.05,1.46)$ & 164 & $2.12(1.75,2.57)$ \\
\hline$p$-trend & & 0.006 & & 0.48 & & 0.007 & & $<0.0001$ \\
\hline \multicolumn{9}{|c|}{ Time since quitting (years) } \\
\hline None $^{\mathrm{b}}$ & 190 & $1.00(\mathrm{ref})$ & 47 & 1.00 (ref) & 166 & 1.00 (ref) & 169 & 1.00 (ref) \\
\hline 1 to $<20$ & 257 & $0.84(0.73,0.98)$ & 61 & $0.77(0.53,1.11)$ & 220 & $0.83(0.70,0.98)$ & 175 & $0.69(0.57,0.82)$ \\
\hline$\geq 20$ & 192 & $0.91(0.77,1.07)$ & 55 & $0.95(0.65,1.41)$ & 159 & $0.88(0.73,1.06)$ & 101 & $0.60(0.48,0.75)$ \\
\hline$p$-trend & & 0.26 & & 0.82 & & 0.16 & & $<0.0001$ \\
\hline
\end{tabular}

${ }^{a}$ Risk ratios are adjusted for age, sex, clinical center, and trial

b Includes current smokers and individuals quitting smoking for $<1$ year

was clearly associated with reduced risk in comparison with continued smoking (RR 0.60; $95 \%$ CI 0.48-0.75) for those quitting 20 or more years ago compared to current smokers. When we examined the association by size, we observed a slightly lower estimated relative risk of serrated lesions greater than $1 \mathrm{~cm}$ (current: RR 1.62, $95 \% \mathrm{CI}$ 1.27-2.07 and former: RR 1.21, $95 \%$ CI $0.98-1.49$ ).

Smoking-associated risks of different polyp types by location in the colorectum are shown in Table 3. For conventional adenomas, risks associated with current smoking appeared slightly higher in the left colorectum (RR 1.50; $95 \%$ CI 1.24-1.83) compared to the right colon (RR 1.27, $95 \%$ CI 1.04-1.55). Risk estimates for packyears, intensity, and duration were similarly higher in the left colorectum versus right colon.
A more marked pattern was evident for serrated polyps. In comparison with never smokers, current smoking was associated with a RR of 2.28 (95\% CI 1.85-2.80) for serrated polyps in the left colorectum, but no increased risk was seen on the right (RR 1.09; $95 \%$ CI 0.75-1.58). As with conventional adenomas, similar patterns were observed for pack-years, intensity, and duration.

Associations between smoking and occurrence of serrated polyps alone were more pronounced (for current smoking vs. never smoking: RR 2.33, $95 \%$ CI 1.76-3.07, Table 4). For the association between smoking and the combination of serrated polyps and adenomas, risk estimates were similar to those of serrated polyps only (for current smoking vs. never smoking: RR 2.27, $95 \%$ CI 1.68-3.06). This pattern was consistently seen for pack-years, smoking intensity and 
Table 3 Association between smoking status, pack-years, and duration and risk of precursor lesions by location in the colorectum

\begin{tabular}{|c|c|c|c|c|c|c|c|c|}
\hline & \multicolumn{4}{|c|}{ Adenomas } & \multicolumn{4}{|c|}{ Serrated polyps } \\
\hline & \multicolumn{2}{|c|}{ Right colon } & \multicolumn{2}{|c|}{ Left colorectum } & \multicolumn{2}{|c|}{ Right colon } & \multicolumn{2}{|c|}{ Left colorectum } \\
\hline & $n$ events & $\mathrm{RR}^{\mathrm{a}}(95 \% \mathrm{CI})$ & $n$ events & $\mathrm{RR}^{\mathrm{a}} 95 \% \mathrm{CI}$ & $n$ events & $\mathrm{RR}^{\mathrm{a}} 95 \% \mathrm{CI}$ & $n$ events & $\mathrm{RR}^{\mathrm{a}} 95 \% \mathrm{CI}$ \\
\hline \multicolumn{9}{|l|}{ Status } \\
\hline Never & 211 & 1.00 (ref) & 200 & 1.00 (ref) & 81 & 1.00 (ref) & 146 & 1.00 (ref) \\
\hline Former & 296 & $1.09(0.93,1.27)$ & 333 & $1.30(1.14,1.52)$ & 108 & $1.11(0.84,1.47)$ & 262 & $1.53(1.27,1.83)$ \\
\hline Current & 116 & $1.27(1.04,1.55)$ & 128 & $1.50(1.24,1.83)$ & 37 & $1.09(0.75,1.58)$ & 140 & $2.28(1.85,2.80)$ \\
\hline$p$-trend & & 0.02 & & $<0.0001$ & & 0.67 & & $<0.0001$ \\
\hline \multicolumn{9}{|l|}{ Pack-years } \\
\hline None & 211 & 1.00 (ref) & 200 & 1.00 (ref) & 81 & 1.00 (ref) & 146 & 1.00 (ref) \\
\hline 0 to $<30$ & 134 & $1.22(1.00,1.49)$ & 133 & $1.28(1.05,1.56)$ & 46 & $1.05(0.73,1.49)$ & 106 & $1.34(1.07,1.68)$ \\
\hline 30 to $<75$ & 108 & $1.05(0.85,1.29)$ & 141 & $1.47(1.21,1.77)$ & 40 & $1.06(0.73,1.53)$ & 139 & $2.05(1.66,2.52)$ \\
\hline$\geq 75$ & 48 & $1.26(0.96,1.67)$ & 50 & $1.42(1.11,1.87)$ & 16 & $1.20(0.71,2.03)$ & 53 & $2.25(1.68,2.99)$ \\
\hline$p$-trend & & 0.24 & & 0.009 & & 0.51 & & $<0.0001$ \\
\hline \multicolumn{9}{|c|}{ Intensity (number of cigarettes per day) } \\
\hline None & 211 & 1.00 (ref) & 200 & 1.00 (ref) & 81 & 1.00 (ref) & 146 & 1.00 (ref) \\
\hline 0 to $<20$ & 87 & $1.29(1.04,1.61)$ & 82 & $1.24(0.99,1.55)$ & 26 & $0.97(0.63,1.48)$ & 59 & $1.27(0.97,1.67)$ \\
\hline 20 to $<30$ & 189 & $1.11(0.93,1.32)$ & 230 & $1.45(1.23,1.71)$ & 72 & $1.19(0.87,1.61)$ & 207 & $1.95(1.61,2.36)$ \\
\hline$\geq 30$ & 132 & $1.07(0.88,1.30)$ & 143 & $1.28(1.05,1.55)$ & 44 & $1.04(0.72,1.50)$ & 132 & $1.73(1.39,2.15)$ \\
\hline$p$-trend & & 0.91 & & 0.005 & & 0.60 & & $<0.0001$ \\
\hline \multicolumn{9}{|c|}{ Duration (years) } \\
\hline None & 211 & 1.00 (ref) & 200 & 1.00 (ref) & 81 & 1.00 (ref) & 146 & 1.00 (ref) \\
\hline 0 to $<25$ & 151 & $1.10(0.92,1.33)$ & 167 & $1.28(1.07,1.54)$ & 58 & $1.11(0.80,1.54)$ & 129 & $1.37(1.11,1.69)$ \\
\hline 25 to $<35$ & 94 & $1.13(0.91,1.40)$ & 110 & $1.42(1.16,1.74)$ & 27 & $0.90(0.59,1.38)$ & 85 & $1.64(1.29,2.08)$ \\
\hline$\geq 35$ & 128 & $1.19(0.97,1.44)$ & 141 & $1.37(1.13,1.66)$ & 45 & $1.19(0.83,1.71)$ & 148 & $2.36(1.91,2.92)$ \\
\hline$p$-trend & & 0.10 & & 0.001 & & 0.59 & & $<0.0001$ \\
\hline \multicolumn{9}{|c|}{ Time since quitting (years) } \\
\hline None $^{\mathrm{b}}$ & 129 & 1.00 (ref) & 141 & 1.00 (ref) & 40 & $1.00(\mathrm{ref})$ & 155 & 1.00 (ref) \\
\hline 1 to $<20$ & 166 & $0.80(0.66,0.98)$ & 178 & $0.79(0.66,0.96)$ & 62 & $0.99(0.68,1.46)$ & 158 & $0.67(0.56,0.82)$ \\
\hline$\geq 20$ & 113 & $0.82(0.65,1.04)$ & 138 & $0.89(0.72,1.10)$ & 41 & $0.95(0.61,1.47)$ & 85 & $0.54(0.43,0.69)$ \\
\hline$p$-trend & & 0.10 & & 0.26 & & 0.82 & & $<0.0001$ \\
\hline
\end{tabular}

${ }^{a}$ Risk ratios are adjusted for age, sex, clinical center, and trial

b Includes current smokers and individuals quitting smoking for $<1$ year

duration, and time since quitting. When we stratified by sex, estimates of risk of smoking status were similar between men and women (Table 5), though with smaller numbers results were not statistically significant in women. Results for smoking exposures defined by pack-years, intensity, and timing also showed similar findings between men and women (data not shown). No significant differences in the estimates of the association between smoking variables and risk by treatment group.

\section{Discussion}

In this combined analysis of three closely followed cohorts participating in adenoma prevention trials, we found strong evidence that cigarette smoking is associated with the development of serrated polyps in the colorectum. In contrast, we found only weak associations between smoking and risk of conventional adenomas (tubular or advanced), and no substantive differences by sex. For both serrated polyps and adenomas, risks associated with smoking were stronger in the left colorectum compared to the right colon. The association with smoking was very similar for participants with serrated polyps only and those with both serrated polyps and adenomas. In examining trends with duration, pack-years, and intensity, higher levels of exposure were consistently associated with higher risk of serrated polyps. Such patterns were not observed consistently for conventional adenomas. 
Table 4 Association between smoking and risk of adenomas, serrated polyps, and concurrent adenomas and serrated polyps

\begin{tabular}{|c|c|c|c|c|c|c|}
\hline & \multicolumn{2}{|c|}{ Only adenomas } & \multicolumn{2}{|c|}{ Only serrated polyps } & \multicolumn{2}{|c|}{ Adenomas and serrated polyps } \\
\hline & $n$ events & $\mathrm{RR}^{\mathrm{a}}(95 \% \mathrm{CI})$ & $n$ events & $\mathrm{RR}^{\mathrm{a}}(95 \% \mathrm{CI})$ & $n$ events & $\mathrm{RR}^{\mathrm{a}}(95 \% \mathrm{CI})$ \\
\hline \multicolumn{7}{|l|}{ Status } \\
\hline Never & 236 & 1.00 (ref) & 91 & 1.00 (ref) & 79 & 1.00 (ref) \\
\hline Former & 318 & $1.15(1.00,1.33)$ & 128 & $1.40(1.09,1.79)$ & 154 & $1.66(1.29,2.13)$ \\
\hline Current & 107 & $1.31(1.08,1.58)$ & 76 & $2.33(1.76,3.07)$ & 66 & $2.27(1.68,3.06)$ \\
\hline$p$-trend & & 0.007 & & $<0.0001$ & & $<0.0001$ \\
\hline \multicolumn{7}{|l|}{ Pack-years } \\
\hline None & 236 & 1.00 (ref) & 91 & 1.00 (ref) & 79 & 1.00 (ref) \\
\hline 0 to $<30$ & 140 & $1.20(1.00,1.44)$ & 52 & $1.19(0.87,1.61)$ & 65 & $1.65(1.22,2.23)$ \\
\hline 30 to $<75$ & 105 & $1.12(0.92,1.36)$ & 65 & $1.76(1.32,2.34)$ & 79 & $2.12(1.59,2.82)$ \\
\hline$\geq 75$ & 44 & $1.28(0.97,1.67)$ & 28 & $2.49(1.67,3.71)$ & 24 & $2.00(1.31,3.05)$ \\
\hline$p$-trend & & 0.14 & & $<0.0001$ & & 0.001 \\
\hline \multicolumn{7}{|c|}{ Intensity (number of cigarettes/day) } \\
\hline None & 236 & 1.00 (ref) & 91 & 1.00 (ref) & 79 & 1.00 (ref) \\
\hline 0 to $<20$ & 100 & $1.30(1.07,1.58)$ & 30 & $1.16(0.79,1.68)$ & 32 & $1.47(1.01,2.12)$ \\
\hline 20 to $<30$ & 184 & $1.16(0.98,1.36)$ & 101 & $1.80(1.40,2.34)$ & 121 & $2.05(1.58,2.64)$ \\
\hline$\geq 30$ & 136 & $1.14(0.95,1.37)$ & 71 & $1.79(1.33,2.40)$ & 65 & $1.65(1.21,2.24)$ \\
\hline$p$-trend & & 0.38 & $<0.0001$ & & & 0.0004 \\
\hline \multicolumn{7}{|c|}{ Duration (years) } \\
\hline None & 236 & 1.00 (ref) & 91 & 1.00 (ref) & 79 & 1.00 (ref) \\
\hline 0 to $<25$ & 161 & $1.15(0.97,1.36)$ & 69 & $1.26(0.96,1.70)$ & 76 & $1.60(1.20,2.14)$ \\
\hline 25 to $<35$ & 111 & $1.31(1.09,1.59)$ & 42 & $1.62(1.16,2.27)$ & 44 & $1.70(1.22,2.39)$ \\
\hline$\geq 35$ & 113 & $1.10(0.92,1.34)$ & 68 & $2.05(1.52,2.79)$ & 82 & $2.18(1.63,2.91)$ \\
\hline$p$-trend & & 0.15 & & $<0.0001$ & & $<0.0001$ \\
\hline \multicolumn{7}{|c|}{ Time since quitting (years) } \\
\hline None $^{\mathrm{b}}$ & 116 & 1.00 (ref) & 82 & 1.00 (ref) & 74 & 1.00 (ref) \\
\hline 1 to $<20$ & 171 & $0.81(0.67,0.98)$ & 78 & $0.58(0.44,0.77)$ & 86 & $0.65(0.49,0.86)$ \\
\hline$\geq 20$ & 134 & $0.89(0.72,1.11)$ & 41 & $0.53(0.37,0.75)$ & 58 & $0.70(0.51,0.96)$ \\
\hline$p$-trend & & 0.30 & & 0.0003 & & 0.03 \\
\hline
\end{tabular}

${ }^{\mathrm{a}}$ Risk ratios are adjusted for age, sex, clinical center, and trial

${ }^{\mathrm{b}}$ Includes current smokers and individuals quitting smoking for $<1$ year

Table 5 Association between smoking status and risk of adenomas, serrated polyps, and concurrent adenomas and serrated polyps stratified by sex

${ }^{a}$ Risk ratios are adjusted for age, sex, clinical center, and trial

\begin{tabular}{|c|c|c|c|c|c|c|}
\hline & \multicolumn{2}{|c|}{ Only adenomas } & \multicolumn{2}{|c|}{ Only serrated polyps } & \multicolumn{2}{|c|}{ Adenomas and serrated polyps } \\
\hline & $n$ events & $\mathrm{RR}^{\mathrm{a}}(95 \% \mathrm{CI})$ & $n$ events & $\mathrm{RR}^{\mathrm{a}}(95 \% \mathrm{CI})$ & $n$ events & $\mathrm{RR}^{\mathrm{a}}(95 \% \mathrm{CI})$ \\
\hline \multicolumn{7}{|l|}{ Men } \\
\hline Never & 207 & 1.00 (ref) & 106 & 1.00 (ref) & 53 & 1.00 (ref) \\
\hline Former & 387 & $1.19(1.04,1.35)$ & 233 & $1.42(1.16,1.73)$ & 124 & $1.48(1.09,2.00)$ \\
\hline Current & 137 & $1.34(1.13,1.58)$ & 103 & $1.90(1.50,2.41)$ & 53 & $2.03(1.41,2.90)$ \\
\hline$p$-trend & & 0.0009 & & $<0.0001$ & & 0.0001 \\
\hline \multicolumn{7}{|l|}{ Women } \\
\hline Never & 108 & 1.00 (ref) & 72 & 1.00 (ref) & 26 & 1.00 (ref) \\
\hline Former & 85 & $1.18(0.93,1.50)$ & 65 & $1.41(1.05,1.89)$ & 30 & $1.86(1.13,3.06)$ \\
\hline Current & 36 & $1.16(0.84,1.60)$ & 49 & $2.22(1.61,3.05)$ & 13 & $1.68(0.89,3.16)$ \\
\hline$p$-trend & & 0.36 & & $<0.0001$ & & 0.12 \\
\hline
\end{tabular}


A few other studies have reported a strong link between smoking and serrated polyps, with point estimates of risk notably higher than for adenomas [6, 10, 11]. Some data suggest that smoking appears to be an important risk factor for SSA/Ps [26-28]. However, we, and other investigators [20], observed no association between smoking and incident serrated polyps in the right colon, where SSA/Ps comprise a significant proportion of serrated polyps. Consistent with our data and others [10-15], the highest smoking-associated risk of serrated lesions is in the left colorectum. The lack of association with right-sided serrated lesions, and the weaker association with large serrated lesions, would suggest that smoking either does not play a significant role in initiation of precursors that give rise to the development of proximal CIMP tumors (which includes most sporadic MSI carcinomas), or that smoking acts at a later stage in the serrated pathway carcinogenic process (i.e., promoting the transition from advanced serrated polyp to MSI cancer). Alternatively, smoking may be linked to colorectal carcinogenesis by effects on the "traditional serrated pathway" via TSA precursor lesions that are typically located in the distal colorectum [29].

The controversy regarding whether or not smoking is associated with CRC [2-4] may be at least in part explained by differences in the two molecular pathways to carcinogenesis. In detailed analyses examining molecular classification of tumors, smoking has been shown to be associated only with a subset characterized by somatic $B R A F$ V600E mutation [30-32], KRAS wild type [33], CIMP [32, 34], and MSI [30, 35, 36], all distinguishing molecular and epigenetic characteristics of the serrated pathway. Smoking is also more strongly associated with proximal versus distal CRC [33, 37, 38]. These data show that smoking acts on the serrated pathway at some point. Our null findings for an association between smoking and serrated lesions in the right colon suggest that this would occur with the conversion of SSA/Ps to carcinoma, potentially via promotion of methylation of MLH1 [39], and therefore, the role of smoking in the initiation phases of polyp development is uncertain. However, compounds in cigarette smoke have been shown to alter DNA methylation patterns in a number of cancer-related genes and genome-wide methylation studies [40]. Furthermore, in a large pooled analysis examining the effect of timing of exposure, smoking cessation (compared to continued smoking) conferred a markedly reduced risk of cancers in right colon, but not in the left colon [4], supporting the idea that smoking may be a key in promoting late pathway progression to serrated carcinomas.

From our prospective clinical trials, we also observed overall estimates of association between smoking and risk of adenomas were weaker (relative risks of 1.2 for former smoking and 1.3 for current smoking) compared to those reported in a previous meta-analysis (relative risks of 1.5 for former smoking and 2.0 for current smoking) [5]. One possible explanation for the difference is that our trial considered incident adenomas in individuals who had all polyps removed at baseline colonoscopies 3-5 years prior, while the previous studies investigated prevalent lesions. If smoking has different effects on initiation versus persistence of adenomas, this could explain the lower risk estimates observed in our study. Furthermore, it is well known that ORs overestimate RR, especially when outcomes are not rare [41].

A few case-control studies [6, 10, 19] suggest that the smoking-associated risk of concurrent adenomas and serrated polyps is even higher than the estimates for the occurrence of only serrated polyps. In these studies, the observed estimates of the OR for current smoking compared to never smoking for both adenomas and serrated lesions ranged from 6.1 to 6.2; the OR estimates for serrated ranged from 4.1 to 4.4 and for adenomas only from 1.3 to 2.0 (Table 6). One additional case-control study by Burnett-Hartman et al. [20] did not observe an elevated risk of concurrent adenomas and serrated polyps versus serrated only, in agreement with our finding. It is not clear why our findings and those of Burnett-Hartman et al. [20] do not agree with earlier publications [6, 10, 19], but in the absence of a definite "separate phenotype" of concurrent adenomas and serrated polyps associated with smoking, the observed association between smoking and conventional adenomas cannot be explained by the inclusion of persons who also have serrated polyps. Smoking must have some effects on adenomas and the chromosomal instability pathway as well.

We did not observe material differences in smokingassociated risks with the size of adenomas or advanced histological features (both components of the advanced adenoma category) or significant heterogeneity by gender, in agreement with some, but not all studies [5, 6, 12]. This may be related to limited sample size when stratifying by gender and polyp characteristics, especially given adenomas are more common in males and the infrequency of advanced adenomas in the pooled studies.

Our study has some limitations and notable strengths. The generalizability of our results may be affected by the fact that all participants in this clinical trial were volunteers who had a previous history of at least one colorectal adenoma, so they represent a restricted part of the colon cancer risk spectrum. Despite expanding upon our earlier study [8] with pooled data across three clinical trials, we had a limited sample size to investigate risk of some of the specific histologic subtypes, in particular after stratification by other patient characteristics such as gender. Furthermore, because our studies were conducted before the current understanding of the serrated pathway had been 
developed, we were unable to subclassify serrated polyps into more meaningful outcome categories. Moreover, since proximal serrated polyp detection by endoscopy is often incomplete [42, 43], it is possible that some participants had undetected proximal serrated lesions, which may have biased our results toward the null for analyses of serrated lesions in particular. We focus here on modeling smoking patterns. Although the pack-years variable could be influenced by intensity in nonadditive terms [44], our results were consistent across multiple smoking variables, contributing to internal validity. The strengths of the current study include pooled analysis of individual-level data from large studies with colonoscopy-based outcome assessment, long follow-up, and systematic collection of patient characteristics in a uniform fashion by the Polyp Prevention Study Group.

In summary, we have found that smoking is associated more strongly with serrated polyps than conventional adenomas and that there is not a "separate phenotype" of smokers with both adenomas and serrated polyps. Multiple lines of evidence now indicate that cigarette smoking is associated both with distal serrated polyps (which are thought to have a lower potential for malignancy) as well as with MSI-H colorectal cancer, which is largely proximal. This apparent paradox could be explained by smoking having multiple effects on serrated pathway carcinogenesis, including initiation of left-sided serrated polyp, as well as a role in later stages of progression from advanced proximal serrated polyps to carcinoma.

Acknowledgments This project has been funded in part with federal funds (N01-CO-12400, R01-CA-059005, U54-CA-100971) from the National Cancer Institute, National Institutes of Health. We thank all the individuals who participated in this clinical trial.

Open Access This article is distributed under the terms of the Creative Commons Attribution License which permits any use, distribution, and reproduction in any medium, provided the original author(s) and the source are credited.

\section{References}

1. Gandini S, Botteri E, Iodice S et al (2008) Tobacco smoking and cancer: a meta-analysis. Int J Cancer 122:155-164

2. Botteri E, Iodice S, Bagnardi V, Raimondi S, Lowenfels AB, Maisonneuve P (2008) Smoking and colorectal cancer: a metaanalysis. JAMA 300:2765-2778

3. Liang PS, Chen TY, Giovannucci E (2009) Cigarette smoking and colorectal cancer incidence and mortality: systematic review and meta-analysis. Int J Cancer 124:2406-2415

4. Gong J, Hutter C, Baron JA et al (2012) A pooled analysis of smoking and colorectal cancer: timing of exposure and interactions with environmental factors. Cancer Epidemiol Biomark Prev 21:1974-1985

5. Botteri E, Iodice S, Raimondi S, Maisonneuve P, Lowenfels AB (2008) Cigarette smoking and adenomatous polyps: a meta-analysis. Gastroenterology 134:388-395 
6. Ji BT, Weissfeld JL, Chow WH, Huang WY, Schoen RE, Hayes RB (2006) Tobacco smoking and colorectal hyperplastic and adenomatous polyps. Cancer Epidemiol Biomark Prev 15: 897-901

7. Reid ME, Marshall JR, Roe D et al (2003) Smoking exposure as a risk factor for prevalent and recurrent colorectal adenomas. Cancer Epidemiol Biomark Prev 12:1006-1011

8. Baron JA, Sandler RS, Haile RW, Mandel JS, Mott LA, Greenberg ER (1998) Folate intake, alcohol consumption, cigarette smoking, and risk of colorectal adenomas. J Natl Cancer Inst 90:57-62

9. Paskett ED, Reeves KW, Pineau B et al (2005) The association between cigarette smoking and colorectal polyp recurrence (United States). Cancer Causes Control 16:1021-1033

10. Morimoto LM, Newcomb PA, Ulrich CM, Bostick RM, Lais CJ, Potter JD (2002) Risk factors for hyperplastic and adenomatous polyps: evidence for malignant potential? Cancer Epidemiol Biomark Prev 11:1012-1018

11. Shrubsole MJ, Wu H, Ness RM, Shyr Y, Smalley WE, Zheng W (2008) Alcohol drinking, cigarette smoking, and risk of colorectal adenomatous and hyperplastic polyps. Am J Epidemiol 167: $1050-1058$

12. Burnett-Hartman AN, Newcomb PA, Mandelson MT et al (2011) Colorectal polyp type and the association with charred meat consumption, smoking, and microsomal epoxide hydrolase polymorphisms. Nutr Cancer 63:583-592

13. Onega T, Goodrich M, Dietrich A, Butterly L (2010) The influence of smoking, gender, and family history on colorectal adenomas. J Cancer Epidemiol 2010:509347

14. Hoffmeister M, Schmitz S, Karmrodt E et al (2010) Male sex and smoking have a larger impact on the prevalence of colorectal neoplasia than family history of colorectal cancer. Clin Gastroenterol hepatol 8:870-876

15. Anderson JC, Moezardalan K, Messina CR, Latreille M, Shaw RD (2011) Smoking and the association of advanced colorectal neoplasia in an asymptomatic average risk population: analysis of exposure and anatomical location in men and women. Dig Dis Sci 56:3616-3623

16. Snover DC (2011) Update on the serrated pathway to colorectal carcinoma. Hum Pathol 42(1):1-10

17. Haque T, Greene KG, Crockett SD (2014) Serrated neoplasia of the colon: what do we really know? Curr Gastroenterol Rep $16: 380$

18. Haque TR, Bradshaw PT, Crockett SD (2014) Risk factors for serrated polyps of the colorectum. Dig Dis Sci 59:2874-2889

19. Fu Z, Shrubsole MJ, Smalley WE et al (2012) Lifestyle factors and their combined impact on the risk of colorectal polyps. Am J Epidemiol 176:766-776

20. Burnett-Hartman AN, Passarelli MN, Adams SV et al (2013) Differences in epidemiologic risk factors for colorectal adenomas and serrated polyps by lesion severity and anatomical site. Am J Epidemiol 177:625-637

21. Wallace K, Grau MV, Ahnen D et al (2009) The association of lifestyle and dietary factors with the risk for serrated polyps of the colorectum. Cancer Epidemiol Biomark Prev 18:2310-2317

22. Greenberg ER, Baron JA, Tosteson TD et al (1994) A clinical trial of antioxidant vitamins to prevent colorectal adenoma. Polyp Prevention Study Group. N Engl J Med 331:141-147

23. Baron JA, Beach M, Mandel JS et al (1999) Calcium supplements for the prevention of colorectal adenomas. Calcium Polyp Prevention Study Group. N Engl J Med 340:101-107

24. Baron JA, Cole BF, Sandler RS et al (2003) A randomized trial of aspirin to prevent colorectal adenomas. N Engl J Med 348: 891-899

25. Lieberman DA, Rex DK, Winawer SJ et al (2012) Guidelines for colonoscopy surveillance after screening and polypectomy: a consensus update by the US multi-society task force on colorectal cancer. Gastroenterology 143:844-857

26. Anderson JC, Rangasamy P, Rustagi $T$ et al (2011) Risk factors for sessile serrated adenomas. J Clin Gastroenterol 45: 694-699

27. Bouwens MW, Winkens B, Rondagh EJ et al (2013) Simple clinical risk score identifies patients with serrated polyps in routine practice. Cancer Prev Res 6:855-863

28. Buda A, De Bona M, Dotti I et al (2012) Prevalence of different subtypes of serrated polyps and risk of synchronous advanced colorectal neoplasia in average-risk population undergoing firsttime colonoscopy. Clin Transl Gastroenterol 3:e6

29. Makinen MJ, George SM, Jernvall P, Makela J, Vihko P, Karttunen TJ (2001) Colorectal carcinoma associated with serrated adenoma-prevalence, histological features, and prognosis. J Pathol 193:286-294

30. Poynter JN, Haile RW, Siegmund KD et al (2009) Associations between smoking, alcohol consumption, and colorectal cancer, overall and by tumor microsatellite instability status. Cancer Epidemiol Biomark Prev 18(10):2745-2750

31. Limsui D, Vierkant RA, Tillmans LS et al (2010) Cigarette smoking and colorectal cancer risk by molecularly defined subtypes. J Natl Cancer Inst 102:1012-1022

32. Samowitz WS, Albertsen H, Sweeney C et al (2006) Association of smoking, CpG island methylator phenotype, and V600E BRAF mutations in colon cancer. J Natl Cancer Inst 98:1731-1738

33. Samadder NJ, Vierkant RA, Tillmans LS et al (2012) Cigarette smoking and colorectal cancer risk by KRAS mutation status among older women. Am J Gastroenterol 107:782-789

34. Nishihara R, Morikawa T, Kuchiba A et al (2013) a prospective study of duration of smoking cessation and colorectal cancer risk by epigenetics-related tumor classification. Am J Epidemiol 178:84-100

35. Slattery ML, Curtin K, Anderson K et al (2000) Associations between cigarette smoking, lifestyle factors, and microsatellite instability in colon tumors. J Natl Cancer Inst 92:1831-1836

36. Yang P, Cunningham JM, Halling KC et al (2000) Higher risk of mismatch repair-deficient colorectal cancer in alpha (1)-antitrypsin deficiency carriers and cigarette smokers. Mol Genet Metab 71:639-645

37. Parajuli R, Bjerkaas E, Tverdal A et al (2013) The increased risk of colon cancer due to cigarette smoking may be greater in women than men. Cancer Epidemiol Biomark Prev 22:862-871

38. Leufkens AM, Van Duijnhoven FJ, Siersema PD et al (2011) Cigarette smoking and colorectal cancer risk in the European prospective investigation into cancer and nutrition study. Clin Gastroenterol Hepatol 9:137-144

39. Gay LJ, Arends MJ, Mitrou PN et al (2011) MLH1 promoter methylation, diet, and lifestyle factors in mismatch repair deficient colorectal cancer patients from EPIC-Norfolk. Nutr Cancer 63:1000-1010

40. Zeilinger S, Kuhnel B, Klopp N et al (2013) Tobacco smoking leads to extensive genome-wide changes in DNA methylation. PLoS One 8:e63812

41. Davies HT, Crombie IK, Tavakoli M (1998) When can odds ratios mislead? BMJ 316:989-991

42. Hetzel JT, Huang CS, Coukos JA et al (2010) Variation in the detection of serrated polyps in an average risk colorectal cancer screening cohort. Am J Gastroenterol 105:2656-2664

43. Kahi CJ, Hewett DG, Norton DL, Eckert GJ, Rex DK (2011) Prevalence and variable detection of proximal colon serrated polyps during screening colonoscopy. Clin Gastroenterol Hepatol 9:42-46

44. Lubin JH, Alavanja MC, Caporaso N et al (2007) Cigarette smoking and cancer risk: modeling total exposure and intensity. Am J Epidemiol 166:479-489 